\title{
Trialling exudate-based enrichment efforts to improve the welfare of rescued slow lorises Nycticebus spp.
}

\author{
A. E. Gray ${ }^{1,2}$, Wirdateti ${ }^{3}$, K. A. I. Nekaris ${ }^{1, *}$ \\ ${ }^{1}$ Little Fireface Project, Nocturnal Primate Research Group, Faculty of Humanities and Social Sciences, \\ Oxford Brookes University, Oxford OX3 0BP, UK \\ ${ }^{2}$ Save the Chimps, Inc., PO Box 12220, Fort Pierce, FL 34945, USA \\ ${ }^{3}$ Research Center for Biology_LIPI, JL. Raya Jakarta-Bogor Km. 46, Jakarta-Bogor, Cibinong 16911, Indonesia
}

\begin{abstract}
Slow lorises Nycticebus spp. are heavily targeted in the illegal animal trade throughout Southeast Asia. Because lorises are venomous, many have their teeth inhumanely removed by animal traders in order to 'tame' them to live as pets or to be used for tourist photography. Confiscated animals are brought to rescue centres where captive care and rehabilitation has proven challenging. Many rescue centres report high mortality, high rates of abnormal behaviour, and low rates of successful reintroductions. Most centres, however, provide little or no gums or saps to these highly specialised exudativorous primates. Our study evaluated the effects of exudatebased enrichment efforts on confiscated wild-born slow lorises at a rescue centre in Java, Indonesia, including methods to provide exudates to animals lacking teeth. We found that these enrichment efforts prolonged foraging and feeding times, but did not reduce abnormal behaviour or promote social behaviour. We found a strong relationship between the amount of time spent on the ground and the time spent performing abnormal behaviour. We discuss the positive implications of prolonging feeding periods, the practicality of each of the enrichment efforts for different types of captive settings, and methods for improving the welfare of captive slow lorises via dietary changes.
\end{abstract}

KEY WORDS: Captive management $\cdot$ Exudativory $\cdot$ Primates $\cdot$ Conservation $\cdot$ Illegal wildlife trade

\section{INTRODUCTION}

The wildlife trade for exotic pets and traditional medicines is a multi-billion dollar industry, resulting in the displacement of millions of fish, birds, reptiles, and mammals from their native habitats (Nijman 2010). For illegally traded wildlife that is confiscated, fates are uncertain, ranging from the euthanasia of confiscated specimens to placement in captive collections or rescue centres (Nijman et al. 2009). In Asia, in particular, the illegal wildlife trade is a major driver towards species extinction (Sodhi et al. 2004). Many animals are maimed in the process, either via live extraction of body parts or fluids (e.g. elephant

*Corresponding author: anekaris@brookes.ac.uk ivory, bear bile; Stiles 2004, Meijaard 1999) for medicines or human aesthetic purposes or to make them less dangerous (e.g. sawing of the sharp teeth of gibbons, defanging tarantulas; Yen \& Ro 2013). In either case, animals are generally destined to live out their lives in captivity, unable to eat or defend themselves in the wild, or die as a result of the procedures.

One such group heavily impacted by the illegal wildlife trade are Asia's slow lorises Nycticebus spp., which are traded for traditional medicines and as photo-props and pets (Nekaris et al. 2009, Starr et al. 2010). Slow lorises occur in 13 Southeast Asian countries and are protected in all of them; all species are listed in Appendix I of CITES (Convention on Inter-

(C) The authors 2015. Open Access under Creative Commons by Attribution Licence. Use, distribution and reproduction are unrestricted. Authors and original publication must be credited. 
national Trade in Endangered Species of Wild Fauna and Flora) (Nekaris \& Nijman 2007). The venomous bite of slow lorises can be harmful to humans (Nekaris et al. 2013a), and thus throughout much of the species' range traders clip the sharp anterior teeth (toothcomb) to prevent the loris from easily delivering its venomous bite. Conducted crudely with wire cutters, nail clippers, or pliers, this procedure causes the death of many animals due to infection (Streicher et al. 2008). Considering that the toothcomb is vital for defence, grooming, socialising with other lorises and, perhaps most importantly, gouging for gum (the most important element of a slow loris's diet) (Wiens et al. 2006, Swapna et al. 2010, Starr \& Nekaris 2013, Streicher et al. 2013, Das et al. 2014), those that survive cannot be returned to the wild (Nekaris et al. 2013b).

More than 25 rescue centres in Asia maintain rescued slow lorises. Offering cheap and locally abundant sugar-rich fruits such as bananas and papaya provides an economic solution to such facilities, which are often on a low budget, and may appear to meet the needs of an animal without teeth. Even in European and North American facilities, however, diets comprising $55 \%$ fruit have yielded problems such as dental disease, diabetes, and obesity (FitchSnyder \& Schulze 2001). Despite exudates being vital for this genus (Starr \& Nekaris 2013), gum arabic is normally offered only as enrichment, if at all (BottcherLaw et al. 2001). Streicher (2004), however, showed in a Vietnamese rescue centre that dental problems in wild-caught pygmy lorises $N$. pygmaeus could be eliminated if the animals were given sufficient substrates to gouge. At the same time, it was found that pygmy lorises fed on high fruit diets (cf. Fitch-Snyder \& Schulze 2001) suffered from tartar and gingivitis (Streicher 2004). Similarly, for captive N. pygmaeus, Cabana \& Plowman (2014) showed how providing a more exudate-based diet not only improved loris health but also reduced stereotypic behaviours.

Stereotypic behaviour is defined by Rushen (1984) and Mason (1993) as invariant, repetitive behaviour with no obvious goal or function. Many researchers suggest that stereotypic behaviour is a sign of distress and/or lack of well-being (Koolhaas et al. 1999, Lutz \& Novak 2005, Tarou et al. 2005, Liu et al. 2006, Maloney et al. 2006). It is sometimes argued that stereotypic behaviour is a calming mechanism in animals (Maloney et al. 2006, Fasano et al. 2008). Stereotypies among rescued slow lorises have been alternately reported as frequent (Moore 2012) or absent (Streicher 2004). Bollen \& Novak (2000) reported that $7 \%$ of strepshirrines, including lorises, found in 108 zoos displayed stereotypic behaviour. Tarou et al. (2005) reported that $13 \%$ of slow lorises observed in 48 AZA (American Zoo and Aquarium Association) accredited institutions displayed stereotypies. Moore \& Nekaris (2011) reported that 33\% of 90 slow lorises at an Indonesian rescue centre displayed stereotypic behaviour, attributing this higher figure to trauma resulting from the pet trade. Collins \& Nekaris (2008) reported 12 deaths out of 19 slow lorises that were undergoing preparation for release; all of these animals showed stereotypic behaviours prior to release. Presence of stereotypies in these studies largely depended on whether the animal had ever been in trade, experienced under- or over-crowding in the captive facility, and been supplied with enrichment in the captive facility.

In this study we attempted to improve the welfare of confiscated slow lorises by introducing exudates into their diet to promote natural feeding and postural behaviours. We also present mechanisms to feed exudates to animals lacking their gouging teeth. We examined if these diet changes have a positive effect on reducing stereotypic behaviours. These results are relevant not only to rescue centres but also to zoos and other captive facilities housing slow lorises and other exudativorous taxa. We examined the utility of different forms of exudate-based enrichment efforts and the use of such devices by slow lorises. We addressed the following questions. Which types of exudate enrichment do slow lorises use? Do slow lorises consuming exudate enrichment perform less stereotypic behaviour? Does exudate enrichment encourage desirable behaviours, including improvement in substrate use?

\section{MATERIALS AND METHODS}

\section{Study site}

International Animal Rescue Indonesia's Ciapus Primate Centre (CPC) is located in Ciapus, near Bogor, Java, Indonesia. Slow lorises are housed in semi-natural outdoor cages with an average size of $5 \times 5 \times 5 \mathrm{~m}$; these cages are built around existing vegetation and neighbour one another. The cages are made of coated wire mesh with semi-translucent roof coverings, which are illuminated with dim red lights. The cages are densely furnished with branches, rubber ropes, nest boxes, naturalistic tunnels made of wood and bamboo, and a variety of foraging substrates, including bamboo feeders and whole cacao fruits with small holes (hereafter referred to as desir- 
able substrates). Lorises also have access to wire mesh and the ground. Hereafter we refer to these as undesirable substrates as CPC veterinarians report hand injuries from excessive mesh use due to the slow loris' strong grip. They also suspect that mice have caused several viral outbreaks and therefore suggest that lorises spend as little time on the ground as possible (see also Fitch-Snyder et al. 2008). Slow lorises are fed twice per night on a diet comprising seasonally available fruits, including bananas cut in pieces and hung about their enclosures, supplemented with grubs and small insects (such as crickets) placed in special feeding boxes. Roughly 100 slow lorises resided at the centre during the time of the study.

\section{Data collection}

\section{Sampling methods}

We collected data from 25 May 2012 to 30 July 2012 between 19:00 and 06:00 h (Nekaris \& Bearder 2011). We used instantaneous scan sampling, with 1 min intervals for all animals within the cage (Altmann 1974). We combined the ethograms of Schulze \& Meier (1995) and Moore \& Nekaris (2011). We observed slow lorises for 30 min or $1 \mathrm{~h}$ segments. We randomly selected cages to observe each night, and we did not observe a cage more than once per night. During each observation we collected data on behaviour, the type of substrate being used (permanent features as described in the previous subsection, including mesh caging; temporary substrates as described in the following subsection), type of foraging enrichment being used, and presence of abnormal behaviours. Abnormal behaviours included: stereotypic head toss (crouching on hind legs and swaying quickly from side to side against the cage), stereotypic pacing (walking to and fro in the cage), stereotypic circling (locomotion in small circles while in suspension), and stress face (prolonged period of flattening ears, mouth turned down, and eyes slightly pursed).

\section{Enrichment conditions}

We divided the study into 5 conditions: baseline, pinecone, banana leaf, grass bundle, and post-experimental. We employed the baseline condition to examine how the slow lorises behaved before introduction to enrichment, and the post-experimental condition served to determine potential lasting effects after the removal of the enrichments (Swaisgood \& Sheperdson 2005, Tarou \& Bashaw 2007, van Praag et al. 2000). Therefore, we expected the lowest amount of desired behaviours to be present in the baseline condition and the highest proportions of desired behaviours amongst the experimental and post-experimental conditions. The enrichments were always given at approximately 19:00 or 24:00 h and were always placed in the high or medium zones of the cage. The experimental enrichments were given in addition to all other enrichment schedules routinely planned for the lorises.

\section{Enrichment assembly}

We collected pinecones from a nearby patch of pine trees and scrubbed them thoroughly in sterilised hot water before applying food products. We spread $7 \mathrm{~g}$ of mashed banana into pinecone grooves and added $5 \mathrm{ml}$ of honey. We spread these ingredients well into the pinecone grooves to make it more challenging for the lorises to retrieve. We attached durable string to the pinecones and hung them from either the top of the cages or from preferred substrates such as branches or rubber ropes.

To establish the 'banana leaf enrichment', we collected fresh branches, between 8 and $12 \mathrm{~cm}$ in diameter, washed them thoroughly with hot sterilised water, and drilled 2 to 4 large holes. The number of holes drilled depended on the number of slow lorises in a cage: 2 holes for 1 slow loris, 3 for 2 slow lorises, and 4 for 3 slow lorises. Jungle Jelly ${ }^{\mathrm{TM}}$ is a viscous acacia-gum-based food with whole mealworms added which remains relatively gelatinous even after prolonged air exposure. Approximately $17 \mathrm{ml}$ of Jungle Jelly ${ }^{\mathrm{TM}}$ was placed in the holes and covered with strips of fresh banana leaf, which we tied to the branch with thin strips of dried banana leaf. We hung these branches horizontally with durable plastic string from the mesh caging or from preferred substrates capable of carrying the extra weight.

We created the 'grass bundle enrichment' with freshly cut long grass that we thoroughly washed with hot sterilised water. We froze the gum in large ice cube trays, with approximately $35 \mathrm{ml}$ of Jungle Jelly $^{\mathrm{TM}}$ in each ice cube slot. We tied the grass bundles with thick plastic string on each end and placed 2 frozen gum cubes in the bundle if there were 1 or 2 slow lorises in the cage, and 3 cubes if there were 3 slow lorises. We added 3 freshly cut, whole fairy duster (Calliandra calothyrsus) flowers to the grass 
bundles to simulate nectar consumption. Once tied at both ends, we hung the bundles from the mesh caging or from substrate enrichment. We put the gums inside the grass bundles, so that, if the frozen gum melted, the contents would not fall to the ground.

Subjects

We observed, collected data on, and analysed the data of 22 individuals in 10 cages ( 1 to 3 animals per cage). Among the 10 cages, we observed all animals, including 6 Javan slow lorises (Nycticebus javanicus, 13 greater slow lorises $N$. coucang), and 3 Philippine slow lorises $N$. menagensis. All of the lorises observed were adults. Five of the individuals were female, and 17 were male. Five lorises in the study had intact teeth, and 17 had teeth clipped and/or removed. The individuals with intact teeth were Singgih, Gheorgie, Passa, Bang One, and Erwin.

\section{Data analysis}

We collected $375 \mathrm{~h}$ of data, with a total of 16404 data points that could be included in analysis. All statistical tests had a significance level of $p<0.05$. We ran mixed linear models to compare behaviour to both fixed and unfixed variables (West et al. 2007). All stereotypic behaviours were combined for analysis into 1 category designated 'abnormal behaviour.' This enabled us to examine how behaviour, substrate use, use of foraging enrichment, and abnormal behaviour changed across conditions.

We recorded substrate data as interacting with temporary substrate, interacting with permanent substrate, or both. Because lorises sometimes used both substrate types simultaneously, we calculated proportions by adding the 'both' category to both other categories. Thus, the proportions of samples spent on temporary and permanent substrates both equal slightly over $100 \%$. If data were not normally distributed, we transformed them by calculating the logarithms with a base of 10 and/or inverse hyperbolic functions (West et al. 2007). If this did not result in a normal distribution, we used the nonparametric Friedman 2-way ANOVA (Dytham 2011).

\section{Ethics}

All procedures followed the guidelines of the Oxford Brookes University Research Ethics Commit- tee and Guidelines for the Use of Animals (Version 2012). Additionally we followed the Guidelines of the Association for the Study of Animal Behaviour in the 2012 edition of Animal Behaviour. We did not handle any animals in this study, and observers always wore a protective mask when viewing the animals to reduce the risk of disease transmission. We always washed enrichments thoroughly with hot water that had been sterilised before placing them in the cage, and the veterinary staff approved all enrichment items before they were used in the study. We excluded any individuals who showed signs of illness from the study.

\section{RESULTS}

\section{Feeding behaviour}

The mixed linear model for feeding/foraging behaviour showed that the feeding behaviour of $\mathrm{Nyc}$ ticebus spp. varied across the cages $\left(F_{(9,13)}=2.981\right.$, $\mathrm{p}=0.035)$, reflecting a difference in individuals. We also found a significant effect of enrichment condition on feeding behaviour $\left(F_{(4,23)}=4.588, \mathrm{p}=0.007\right)$. The effect of the conditions was stronger than the effect of individual differences, meaning that differences in behaviour can largely be attributed to the experimental enrichments. The greatest difference was in the pinecone condition, where feeding behaviour was significantly increased compared to the post-experimental condition $(\mathrm{p}=0.008)$, but was not significantly increased compared to the baseline condition ( $p=0.221$ ) (Fig. 1). In the banana leaf condition, feeding behaviour was significantly more prevalent than in the post-experimental condition $(\mathrm{p}=$ 0.015 ) and approached significance compared to the baseline condition ( $p=0.061$ ). No significant differences were found for the grass bundle condition.

\section{Active behaviours}

'Individual' $\left(F_{(9,19)}=3.744, \mathrm{p}=0.008\right)$ and 'condition' $\left(F_{(4,13)}=3.848, \mathrm{p}=0.027\right)$ both had a significant effect on exploratory behaviour, with individual showing a stronger effect than condition. In the pinecone condition, the animals showed significantly less exploratory behaviour than in the other conditions, with an average of $0.9 \%$ of sample points spent performing exploratory behaviour. The averages of exploratory behaviour for animals in the other conditions were: $5.2 \%$ in baseline, $5.6 \%$ in 


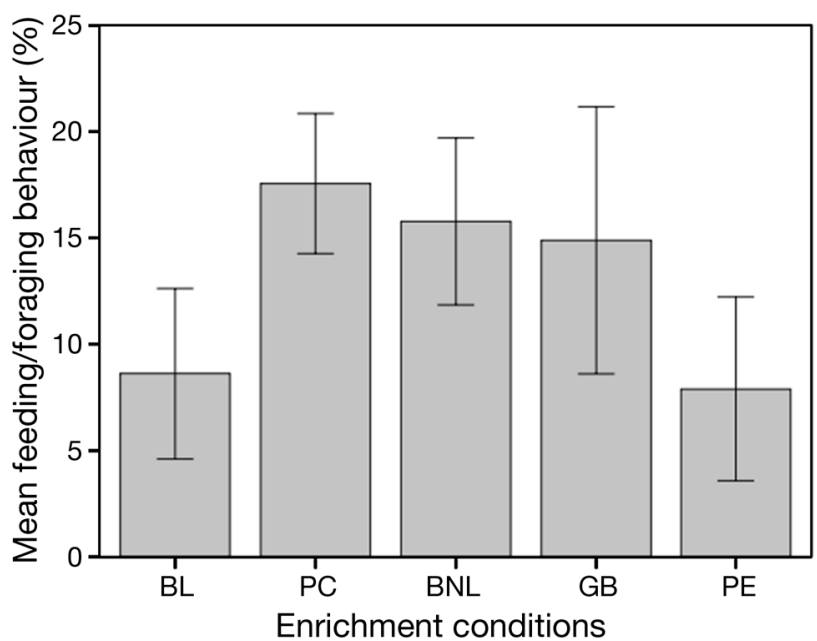

Fig. 1. Nycticebus spp. Mean feeding behaviours across enrichment conditions. Both the pinecone and banana leaf conditions significantly increased foraging behaviours when compared to the post-experimental condition. BL: baseline condition; PC: pinecone enrichment; BNL: banana leaf enrichment; GB: grass bundle enrichment; PE: post-experimental condition. Error bars $=95 \%$ confidence intervals

banana leaf, $3.0 \%$ in grass bundle, and $5.6 \%$ in the post-experimental condition. Other than the pinecone condition, we found no significant differences in pairwise comparisons between conditions. Friedman 2-way ANOVAs showed that the remaining active categories did not significantly change across conditions: aggressive behaviour $\left(\chi^{2}(4)=5.460, \mathrm{p}=\right.$ $0.243)$; play behaviour $\left(\chi^{2}(4)=4.387, \mathrm{p}=0.356\right)$; social behaviour $\left(\chi^{2}(4)=4.727, \mathrm{p}=0.316\right)$; locomotion $\left(\chi^{2}(4)\right.$ $=4.000, \mathrm{p}=0.406)$.

\section{Abnormal behaviour}

Abnormal behaviour did not significantly change across baseline, pinecone, banana leaf, grass bundle, and post-experimental conditions $\left(\chi^{2}(4)=2.095, \mathrm{p}=\right.$ $0.718)$. Differences in levels of abnormal behaviours occurred between cages (Fig. 2). Significantly high levels of stereotypic behaviour were only observed in Cages 6, 7, 9, and 10, all of which housed greater slow lorises ( $N$. coucang) (Friedman 2-way ANOVA, $\left.\chi^{2}(9)=38.603, p=0.0001\right)$.

\section{Experimental conditions and substrate preference}

Across pinecone, banana leaf, and grass bundle conditions we found no significant difference in time

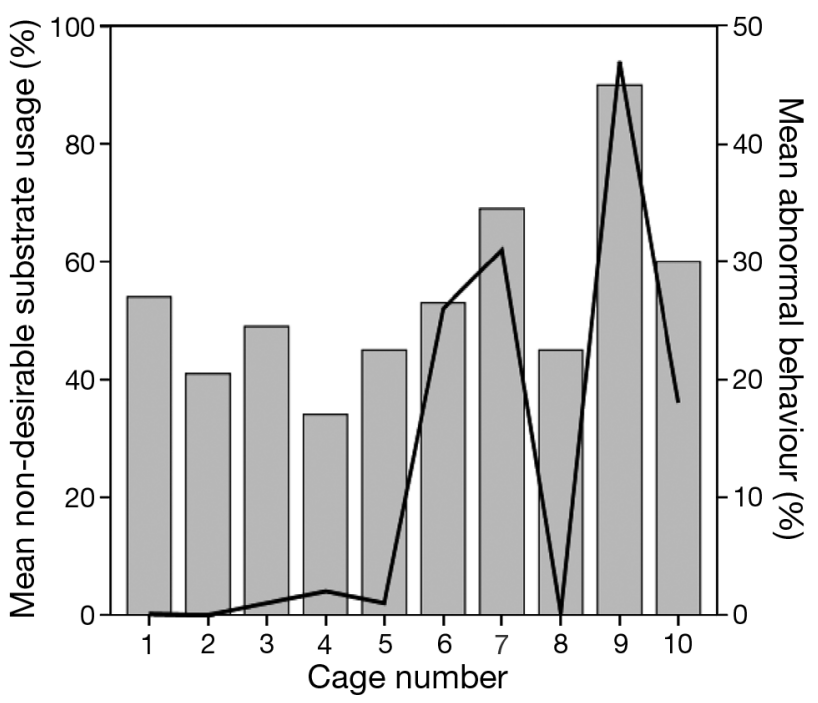

Fig. 2. Nycticebus spp. Significant relationship between the amount of time spent engaging in abnormal behaviour (solid line) and using non-desirable substrates (grey bars) (Spearman's correlation, $\left.\mathrm{r}_{48}=0.606, \mathrm{p}<0.001\right)$. Non-desirable substrates include the ground and wire mesh, both of which are undesirable areas for loris locomotion due to increased likelihood of terrestrial disease transmission and hand injuries on the wire mesh

the lorises spent interacting with the enrichments $\left(\chi^{2}(2)=1.400, p=0.497\right)$. We ran 2 mixed linear models for interaction with substrates to examine how much time the lorises spent on 'desirable substrates' (branches, rubber ropes, tunnels, etc.) versus 'nondesirable substrates' (mesh caging and ground). The model examining time spent on substrate enrichment showed that enrichment conditions had a significant effect $\left(F_{(4,12)}=5.330, \mathrm{p}=0.010\right)$, as did individual differences $\left(F_{(8,13)}=16.040, \mathrm{p}<0.001\right)$. Pairwise comparisons showed that within conditions, the only significance lies in the post-experimental condition, in which the lorises spent significantly less time on desirable substrates compared to all other conditions.

Both models showed that individual differences were larger than the effects of the enrichment conditions. As was the case for abnormal behaviour, Cages 7 (Passa), 9 (Erwin), and 10 (Tupper and Cepat) showed the greatest differences in substrate preference. We found a relationship between the amount of time spent using non-desirable substrates, particularly the ground, and abnormal behaviour, as both stereotypic pacing and head tossing usually take place on the ground (Fig. 2). Accordingly Spearman's correlation showed a significant correlation between the time spent using non-enrichment substrates and abnormal behaviour $\left(\mathrm{r}_{48}=0.606, \mathrm{p}<0.001\right)$. 


\section{DISCUSSION}

We present several key findings with implications for captive care of slow lorises. Of the environmental enrichment conditions, the banana leaf and pinecone conditions encouraged the most significant increase in feeding behaviour. Overall, the banana leaf condition promoted feeding most successfully without creating a decrease in exploratory behaviour, play behaviour, or resting behaviour. Whilst slow lorises showed no significant preference among the enrichments, they spent the most time feeding on and foraging for the enrichment than for their normal diet. These conditions are a cost-effective and efficient way to provide these exudativorous primates with a key naturalistic component of their diet, as well as preparing those suitable for release with an active opportunity to seek exudates.

Animal care staff at CPC stated that, of the 3 experimental conditions, they preferred the pinecone enrichment because it was simple to assemble and easy to clean. Additionally, the pinecones were not easily subject to mould. The banana leaf condition, while effective in promoting feeding behaviours, became mouldy so quickly that we sometimes could not use the same branch for more than 2 nights. Indoor facilities such as zoos, or rescue centres with less humidity may be able to counter this problem. For outdoor facilities in areas of high humidity, building gum feeders out of bamboo or PVC pipes may prove more practical. The grass bundle condition did not mould quickly, but its assembly was more involved than that of the pinecone enrichment. Thus, the practicality of each enrichment type will vary across institutions, based on the number of keepers, available resources, and enclosure type.

We found a difference between the rates of abnormal behaviour among individuals. Nycticebus coucang exhibited the highest levels of abnormal behaviour. Future studies should prioritise investigating species differences in rates of abnormal behaviour.

Despite the fact that our experimental enrichment items did not reduce abnormal behaviours, it is encouraging that feeding and foraging behaviours increased. Hogan \& Tribe (2007) argue that a major problem for wild animals in captivity is the use of strict feeding schedules, as such schedules produce predictable feeding patterns that are very different from foraging strategies in the wild. Furthermore, when wild feeding patterns are disrupted, redirected behaviours such as stereotypies produce feedback, acting as a substitute for natural feeding behaviours. Indeed, Mason \& Mendl (1997) found that food restric- tion increases stereotypic behaviour, which, in turn, decreases when natural foraging options are provided. It is possible that exudate-based enrichment could alter the rate of stereotypic behaviours over a longer period of time; therefore, future studies should aim at covering a more extensive time period. Whilst including exudates in the diet is necessary for health and potentially reduces abnormal behaviour (Cabana \& Plowman 2014), other aspects of captivity should also be investigated, including social groupings, lighting, cage size, cage rotation, food schedules, and providing short bouts of 'healthy' stress.

We designed our conditions to encourage slow lorises to use desirable substrates. Slow lorises that spent the most time on the ground and wire mesh also showed the highest levels of abnormal behaviour, which is often performed on the ground. Our enrichments did not reduce the amount of time spent on the ground or on the mesh caging. Keeping slow lorises away from non-desirable substrates is particularly important for health reasons. Slow lorises face an increased infection risk whilst moving on the ground (Fitch-Snyder et al. 2008) and an additional risk due to the compromised immune system that comes with high levels of stereotypic behaviour (Carlstead \& Brown 2005, McPhee \& Carlstead 2010). Reducing abnormal behaviour will help reduce the amount of time lorises spend on the ground, but finding ways to keep the lorises off the mesh might prove more difficult. Slow lorises tend to prefer continuous substrates around which they can wrap their hands. In a rescue centre setting, wire mesh is an appealing option, as it is inexpensive, allows airflow, and is easy to erect. Although wire mesh is recommended as part of an enclosure (Bottcher-Law et al. 2001, Hanna 2006), it can cause destructive and even fatal hand injuries. One solution might be to cover parts of the wire mesh with a non-grip sheeting (e.g. aluminium) to encourage slow lorises to use other offered substrates and to ensure that plenty of continuous substrate opportunities throughout the cage are offered (Fitch-Snyder et al. 2008).

Few recommendations are available on characterising and reducing stereotypic behaviours in nocturnal primates. Tarou et al. (2005) reported that, of 48 institutions, nearly half have attempted to reduce or eliminate stereotypies with enrichment and training schemes; $58 \%$ have claimed to be partially if not fully successful. Training may not be an option for animals that are likely to go back to the wild, and, therefore, environmental enrichment is one of the few options to decrease stereotypic behaviour in these sensitive and cryptic species. 
Our enrichment promoted many species-typical exudativorous behaviours (Starr \& Nekaris 2013). Most of the slow lorises eagerly lapped the gums and hung in suspensory postures to reach these items, but even the 5 animals with teeth did not gnaw into the wood or pinecones. All animals still had their molar teeth, and, although chewing with molars has been observed in the wild, this behaviour did not occur in our study. The only instances of gouging behaviour recorded were 4 scans in the post-experimental condition, performed by Cepat - a loris without anterior teeth. The Jungle Jelly ${ }^{\mathrm{TM}}$ is viscous, and, although it hardens slightly upon prolonged air exposure, it does not fully harden or stick strongly to the substrate in which it is placed, meaning that gouging was not necessary. The CPC slow lorises have been observed to gouge wooden substrates in their cages. Several types of gum arabic are on the market, including canned or jarred gums and those in powdered form to which one must add water (Huber \& Lewis 2011). Different types can be experimented with to determine which harden the most and encourage the highest rates of gouging. Moreover, making difficult for lorises to reach the exudates, as done for each enrichment type in the present study, increases the amount of time the animals interact with the enrichment, whether or not they gouge to obtain it.

Our experimental enrichments did not significantly promote any social behaviours, including grooming. As with gouging, it may be too difficult for slow lorises to perform this particular social behaviour properly once their teeth have been severely damaged in the pet trade.

Because lorises are specialised exudativores, it is essential to incorporate gums and saps into their diets in captivity. Thus far, reintroductions to the wild have had a high rate of failure, including lorises dying of starvation and exhaustion (Moore 2012, Kenyon et al. 2014). During rehabilitation at rescue centres, encouraging lorises to consume exudates will maintain the suite of behaviours associated with their consumption, which is vital for reintroduction programmes. Moreover, maintaining a low-calorie, high-energy diet, including exudates and nectar, is necessary to avoid obesity in rescue centres, zoos, and other captive settings. Promoting gouging in captivity will also greatly assist in overall dental health for lorises with intact teeth. Designing exudate-based enrichment that prolongs feeding periods may additionally reduce abnormal behaviours over long periods of time. Future studies should examine the long-term health benefits of an exudate-rich diet.
We hope that the mechanisms we have presented here will provide a foundation for other captive facilities hoping to introduce gum-based enrichment to species whose nutritional requirements deem it necessary.

Acknowledgements. We thank A. Knight of International Animal Rescue and the staff at Ciapus Primate Centre. In particular, we thank K. L. Sanchez, veterinarians S. Paramasivam and W. Parmeswari, and the keepers who contributed their knowledge of loris care and enrichment construction, including E. Mursid, M. Jakaria, A. Barnas, F. Taufiq, I. Rosadi, and D. Permana. R. Moore, V. Nijman, and G. Donati provided valuable advice. We appreciate the thorough comments of 3 anonymous reviewers and C. Starr which improved the quality of the manuscript. We thank Exotic Animal Nutrition for their generous donation of Jungle Jelly ${ }^{\mathrm{TM}}$. The study was funded by the Leverhulme Trust (RPG-084), Universities Federation for Animal Welfare, Conservation International's Primate Action Fund, People's Trust for Endangered Species, and International Primate Protection League.

\section{LITERATURE CITED}

Altmann J (1974) Observational study of behavior: sampling methods. Behaviour 49:227-266

Bollen KS, Novak MA (2000) A survey of abnormal behavior in captive zoo primates. Am J Primatol 51:1-47

Bottcher-Law L, Fitch-Snyder H, Hawes J, Larsson L and others (2001) A husbandry manual for Asian lorisines (Nycticebus \& Loris spp.). Center for Reproduction of Endangered Species, San Diego, CA

Cabana F, Plowman A (2014) Pygmy slow loris Nycticebus pygmaeus-natural diet replication in captivity. Endang Species Res 23:197-204

> Carlstead K, Brown JL (2005) Relationships between patterns of fecal corticoid excretion and behavior, reproduction, and environmental factors in captive black (Diceros bicornis) and white (Ceratotherium simum) rhinoceros. Zoo Biol 24:215-232

Collins R, Nekaris KAI (2008) Release of greater slow lorises, confiscated from the pet trade, to Batutegi Protected Forest, Sumatra, Indonesia. In: Soorae PS (ed) Global reintroduction perspectives. IUCN Reintroduction Specialist Group, Abu Dhabi, p 192-195

Das N, Nekaris KAI, Bhattacharjee PC (2014) Medicinal plant exudativory by the Bengal slow loris Nycticebus bengalensis. Endang Species Res 23:149-157

Dytham C (2011) Choosing and using statistics: a biologist's guide, 3rd edn. Blackwell Science, Chichester

Fasano A, Barrab A, Nicosiab P, Rinaldib F, Briab P, Bentivoglioa AR, Tonionib F (2008) Cocaine addiction: from habits to stereotypical-repetitive behaviors and punding. Drug Alcohol Depend 96:178-182

Fitch-Snyder H, Schulze H (eds) (2001) Management of lorises in captivity: a husbandry manual for Asian lorisines (Nycticebus \& Loris spp.). Center for Reproduction of Endangered Species, Zoological Society of San Diego, CA

Fitch-Snyder H, Schulze H, Streicher U (2008) Enclosure design for captive slow and pygmy lorises. In: Shekelle 
M, Maryanto I, Groves C, Schulze H, Fitch-Snyder H (eds) Primates of the oriental night. LIPI Press, Jakarta, p 123-135

Hanna JB (2006) Kinematics of vertical climbing in lorises and Cheirogaleus medius. J Hum Evol 50:469-478

Hogan LA, Tribe A (2007) Prevalence and cause of stereotypic behaviour in common wombats (Vombatus ursinus) residing in Australian zoos. Appl Anim Behav Sci 105: 180-191

> Huber HF, Lewis KP (2011) An assessment of gum-based environmental enrichment for captive gumnivorous primates. Zoo Biol 30:71-78

- Kenyon M, Streicher U, Loung H, Tran T, Tran M, Bo V, Cronin A (2014) Survival of reintroduced pygmy slow loris Nycticebus pygmaeus in South Vietnam. Endang Species Res 25:185-195

Koolhaas JM, Korte SM, De Boer SF, Van Der Vegt BJ and others (1999) Coping styles in animals: current status in behaviour and stress-physiology. Neurosc Biobehav Rev 23:925-935

Liu J, Chen Y, Guo L, Gu B and others (2006) Stereotypic behavior and fecal cortisol level in captive giant pandas in relation to environmental enrichment. Zoo Biol 25: 445-459

Lutz CK, Novak MA (2005) Environmental enrichment for nonhuman primates: theory and application. ILAR J 46: 178-191

Maloney MA, Meiers ST, White J, Romano MA (2006) Effects of three food enrichment items on the behaviour of black lemurs (Eulemur macaco macaco) and ringtail lemurs (Lemur catta) at the Henson Robinson Zoo, Springfield, Illinois. J Appl Anim Welf Sci 9:111-127

Mason GJ (1993) Forms of stereotypic behaviour. In: Lawrence AB, Rushen J (eds) Stereotypic animal behaviour: fundamentals and applications to welfare. Cab International, Wallingford, p 7-40

Mason GJ, Mendl M (1997) Do the stereotypies of pigs, chickens and mink reflect adaptive species differences in the control of foraging. Appl Anim Behav Sci 53:45-58

McPhee ME, Carlstead K (2010) The importance of maintaining natural behaviors in captive mammals. In: Kleiman DG, Thompson KV, Baer CK (eds) Wild mammals in captivity: principles \& techniques for zoo management. The University of Chicago Press, Chicago, IL, p 303-313

Meijaard E (1999) Human-imposed threats to sun bears in Borneo. Ursus 1999:185-192

Moore RS (2012) Ethics, ecology, and evolution of Indonesian slow lorises (Nycticebus spp.) rescued from the pet trade. PhD dissertation, Oxford Brookes University, Oxford

Moore RS, Nekaris KAI (2011) Stereotypic behaviours in Indonesian slow lorises (Nycticebus spp.) at a rescue centre in Java: implications for rehabilitation and release. In: Proc 4th Congress of the European Federation for Primatology, 3rd Iberian Primatological Congress. Central Library, Almada

Nekaris KAI, Bearder SK (2011) The lorisiform primates of Asia and mainland Africa: diversity shrouded in darkness. In: Campbell CJ, Fuentes A, MacKinnon KC, Bearder SK, Stumpf RM (eds) Primates in perspective. Oxford University Press, Oxford, p 34-54

Nekaris KAI, Nijman V (2007) CITES proposal highlights rarity of Asian nocturnal primates (Lorisidae: Nycticebus). Folia Primatol (Basel) 78:211-214
Nekaris KAI, Llano Sanchez K, Thorn JS, Winarti I, Nijman V (2009) Javan slow loris Nycticebus javanicus E. Geoffroy, 1812, Indonesia. In: Mittermeier RA, Wallis J, Rylands AB, Ganzhorn JU and others (eds) Primates in peril: the world's 25 most endangered primates 20082010. Primate Conserv 24:44-46

Nekaris KAI, Moore RS, Rode EJ, Fry BG (2013a) Mad, bad and dangerous to know: the biochemistry, ecology and evolution of slow loris venom. J Ven Anim Tox incl Trop Dis 19: article 21

Nekaris KAI, Campbell N, Coggins TG, Rode EJ, Nijman V (2013b) Tickled to death: analysing public perceptions of 'cute' videos of threatened species (slow lorises - Nycticebus spp.) on Web 2.0 sites. PLoS ONE 8:e69215

Nijman V (2010) An overview of international wildlife trade from Southeast Asia. Biodivers Conserv 19:1101-1114

> Nijman V, Yang-Martinez CF, Shepherd CR (2009) Saved from trade: donated and confiscated gibbons in zoos and rescue centres in Indonesia. Endang Species Res 9:151-157

Rushen J (1984) Stereotyped behaviour, adjunctive drinking and the feeding periods of tethered sows. Anim Behav 32:1059-1067

Schulze H, Meier B (1995) Behaviour of captive Loris tardigradus nordicus: a qualitative description, including some information about morphological bases of behaviour. In: Alterman L, Doyle A, Izard MK (eds) Creatures of the dark: the nocturnal prosimians. Plenum Press, New York, NY, p 221-249

Sodhi NS, Koh LP, Brook BW, Ng PK (2004) Southeast Asian biodiversity: an impending disaster. Trends Ecol Evol 19: $654-660$

Starr C, Nekaris KAI (2013) Obligate exudativory characterizes the diet of the pygmy slow loris Nycticebus pygmaeus. Am J Primatol 75:1054-1061

> Starr CR, Nekaris KAI, Streicher U, Leung L (2010) Traditional use of slow lorises Nycticebus bengalensis and $N$. pygmaeus in Cambodia: an impediment to their conservation. Endang Species Res 12:17-23

Stiles D (2004) The ivory trade and elephant conservation. Environ Conserv 31:309-321

Streicher U (2004) Confiscated primates - health aspects and long-term placement options. In: Nadler T, Streicher U, Ha TL (eds) Conservation of primates in Vietnam. Frankfurt Zoological Society, Frankfurt, p 154-160

Streicher U, Schulze H, Fitch-Snyder H (2008) Confiscation, rehabilitation and placement of slow lorises. Recommendations to improve the handling of confiscated slow lorises Nycticebus coucang. In: Shekelle M (ed) Primates of the oriental night. LIPI, Jakarta, p 137-145

Streicher U, Wilson A, Collins RL, Nekaris KAI (2013) Exudates and animal prey characterize the slow loris diet in captivity and after release into the wild. In: Masters J, Gamba M, Genin F (eds): Leaping aheadadvances in prosimian biology. Springer, Heidelberg, p 165-172

> Swaisgood RR, Sheperdson DJ (2005) Scientific approaches to enrichment and stereotypies in zoo animals: What's been done and where should we go next? Zoo Biol 24: 499-518

> Swapna N, Radahkrishna S, Gupta AK, Kumar A (2010) Exudativory in the Bengal slow loris (Nycticebus bengalensis) in Trishna Wildlife Sanctuary, Tripura, Northeast India. Am J Primatol 72:113-121

> Tarou LR, Bashaw MJ (2007) Maximizing the effectiveness 
of environmental enrichment: suggestions from the experimental analysis of behavior. Appl Anim Behav Sci 102:189-204

Tarou LR, Bloomsmith MA, Maple TA (2005) Survey of stereotypic behavior in prosimians. Am J Primatol 65: 181-196

van Praag H, Kempermann G, Gage FH (2000) Neural consequences of environmental enrichment. Nat Rev Neurosci 1:191-198

Editorial responsibility: Carly Starr,

Gatton, Australia
West B, Welch KB, Galecki AT (2007) Linear mixed models: a practical guide using statistical software. Taylor \& Francis, Boca Raton, FL

Wiens F, Zitzmann A, Hussein NA (2006) Fast food for slow lorises: Is low metabolism related to secondary compounds in high-energy plant diet? J Mamm 87:790-798

Yen AL, Ro S (2013) The sale of tarantulas in Cambodia for food or medicine: Is it sustainable? J Threatened Taxa 5: 3548-3551

Submitted: August 1, 2013; Accepted: October 14, 2014 Proofs received from author(s): December 17, 2014 